\title{
Conectividades plenas redimensionam a comunicação contemporânea
}

\section{Sebastião Carlos de Morais Squirra ${ }^{1}$}

Recibido: 2016-01-16

Enviado a pares: 2016-01-17
Aprobado por pares: 2016-03-02

Aceptado: 2016-03-17

DOI: 10.5294/pacla.2017.20.1.8

Para citar este artículo / to reference this article / para citar este artigo

De Morais Squirra, S. C. (2017). Conectividades plenas redimensionam a comunicação contemporânea. Palabra Clave, 20(1), 162-183. DOI: 10.5294/pacla.2017.20.1.8

\section{Resumo}

A comunicação é um recurso intrínseco à condição humana e, por isso, é largamente estudada. Neste texto, trabalhamos com o princípio de que a comunicação na essência se constitui como um processo neurológico que tem sua gênese e nicho de existência no cérebro das pessoas. Assim, a partir das mensagens absorvidas pelos canais da sensibilidade humana, o processo biológico direciona informações para a decodificação e interpretação nesse importante órgão. Nosso estudo tem metodologia baseada em modelo investigativo interdisciplinar e centra-se em referências bibliográficas e no que já é cientificamente comprovado na neurociência. Dessa forma, e ao cruzar com autores da comunicação, indagamos se em determinado momento o acesso aos produtos comunicativos poderá se concretizar no cérebro humano e superar a histórica mediação das mídias físicas. Ao alargar os referenciais teóricos, amparamo-nos também em autores da física e da biologia, sobretudo nas conquistas das investigações neurobiológicas que, somadas à incessante miniaturização tecnológica, alicerçam pressupostos científicos que nos permitiram adentrar a impensada possibilidade comu-

1 Universidade Metodista de São Paulo, Brasil. sebastiao.squirra@metodista.br 
nicativa do acesso por pensamentos. Isso se apresenta como seguro uma vez que se experimenta tempos de diálogos homem-máquinas em profusão interativa inédita, com plataformas e aplicativos o tempo todo conectados, condições que aprumam o caminho para prevermos o acesso mental aos conteúdos audiovisuais.

\section{Palavras-chave}

Neurobiologia; acesso à informação; tecnologia da comunicação; cognição; comunicação de massa (Fonte: Unesco Thesaurus). 


\section{Las conectividades plenas redimensionan la comunicación contemporánea}

\section{Resumen}

La comunicación es un recurso intrínseco de la condición humana y, por tanto, es ampliamente estudiada. En este texto, trabajamos con el principio de que la comunicación en esencia se constituye como un proceso neurológico que tiene su génesis y nicho de existencia en el cerebro de las personas. Así, a partir de los mensajes absorbidos por los canales de la sensibilidad humana, el proceso biológico direcciona informaciones para la decodificación e interpretación en ese importante órgano. La metodología está basada en un modelo investigativo interdisciplinar centrado en referencias bibliográficas y en lo que ya es científicamente comprobado en la neurociencia. De este modo, y al referenciar autores de la comunicación, indagamos si en determinado momento el acceso a los productos comunicativos podrá concretizarse en el cerebro humano y superar la histórica mediación de los medios físicos. Al agrandar los referenciales teóricos, nos amparamos también en autores de física y biología, sobre todo en las conquistas de las investigaciones neurobiológicas que, sumadas a la incesante miniaturización tecnológica, amparan presupuestos científicos que nos permitirán adentrar la impensada posibilidad comunicativa del acceso por pensamientos. Esto se presenta como seguro una vez que se experimentan tiempos de diálogos hombre-máquinas en profusión interactiva inédita, con plataformas y aplicaciones permanentemente conectados, condiciones que apuntan el camino para prever el acceso mental a los contenidos audiovisuales.

\section{Palabras clave}

Neurobiología; acceso a la información; tecnología de la comunicación; cognición; comunicación masiva (Fuente: Tesauro de la Unesco). 


\section{Full Connectivity Resizes Contemporary Communication}

\section{Abstract}

Communication is an intrinsic resource to humanity and is therefore widely studied. This paper is based on the principle that communication is essentially a neurological process that starts and exists in people's brains. Therefore, and based on the messages absorbed by the channels of human sensibility, the biological process directs information for decoding and interpretation in this major organ. The methodology used in our study is based on an interdisciplinary research model and focuses on bibliographical references and on what is already scientifically proven in neuroscience. Thus, and after reviewing some authors addressing communication, we question if, at any given time, access to communication products can be realized in the human brain and overcome the historical mediation of physical media. By broadening the theoretical frameworks, we also draw on authors of physics and biology, particularly in the achievements of neurobiological investigations, which, in addition to the incessant technological miniaturization, establishes a few scientific presuppositions that allowed us to enter into the unthinking communicative possibility of access by thoughts. This appears as safe, in that you experience times of man-machine dialogues in unprecedented interactive profusion, with platforms and applications that are permanently connected, which are conditions that pave the way for mental access to audiovisual content.

\section{Keywords}

Neurobiology, access to information, communication technology, cognition, mass communication (Source: Unesco Thesaurus). 


\section{Introdução}

Construídas com tecnologias e recursos do mundo material e captadas pelos sentidos, as muitas formas da comunicação se materializam nos gigantescos e largamente estudados processos sinápticos que ocorrem nos cérebros, um dos mais importantes órgãos dos seres vivos. Observando pressupostos e descobertas da neurobiologia, inferimos que as sinapses são processos essencialmente comunicativos uma vez que se caracterizam por transmitir informações de uma célula para outra por meio da troca de sinais elétricos e químicos. Assim, podem ser entendidas como cadeias de processamento, transmissão e recepção de informação que apontam os predicados que representam a razão dos processos da comunicação. Dessa forma, e por analogia reversa, postulamos que a comunicação possa ser enquadrada como um processo neurológico pois se materializa nos estímulos nervosos que sensibilizam sensores localizados na visão, no ouvido e na fala, dentre outros. A comunicação é, fisiologicamente falando, um fenômeno que se concretiza nos estímulos realizados na mente e, no presente texto, nos referimos à mente humana.

Na comunicação, importantes estudos foram feitos na compreensão do campo (Mattelart e Mattelart, 2003; Toffler, 1992; McLuhan, 1964), no enquadramento das muitas plataformas midiáticas (Mattelart, 2002; Canton, 2001; Jenkins, 2014, entre outros) e mais recentemente daquelas possibilidades advindas com a informatização e a tecnologização da vida pós-moderna (Castells, 2003; Pavlik, 2008, entre outros.). Todavia, nesse conjunto, percebemos que faltam pesquisas recortadas na codificação e decodificação de conteúdos, sobre os processos que ocorrem, em primeira instância, no cérebro humano. Na maior parte do tempo, pesquisadores da comunicação realizam reflexões que pautam as características, políticas e abrangências dos suportes que veiculam os enunciados (Castells, 1999; Vilches, 2003; Bagdikian, 1993) e em expressivas investigações sobre as elaborações de conteúdos (intenções dos emissores), e os consequentes efeitos dos enunciados no ponto de "chegada" nos receptores (Machado, 2000; Bliss Jr, 1991; Head e Sterling, 1990, entre outros). O enorme volume de informação que circula na atualidade faz com que o coletivo social se sacie de comunicação por meio dos intercâmbios realizados pelo fértil parque 
de inovações tecnológicas (Dertouzos, 1997; Gilder, 2001; Jenkins, 2009; Johnson, 2001; Wolton, 2000; Rifkin, 2001). Tal realidade está corrigindo a estratificada carência dialógica do período analógico anterior e vem viabilizando a inclusão e integração sociais, fenômenos possíveis com a larga adoção das tecnologias da pós-modernidade. A forte adesão tecnológica revela o estrondoso sucesso dos aparatos comunicativos e explicita perceptíveis alterações cognitivas, culturais e sensoriais nos usuários. Mudam os processos comunicativos e mudam também os cérebros dos seres humanos, pois se sabe que tal incremento de acoplamentos permite o acesso a um volume muito maior de conhecimento (Kurzweil, 2007; Kaku, 2012) em virtude da pluralidade tecnológica composta por suportes midiáticos variados, móveis e o tempo todo conectados (Rifkin, 2001). O cenário define a cibercomunicação, um território de expressão em que tudo são imagens, animações e sons, em plataformas individuais, mas totalmente integradas e convergentes. Sublinhamos que a absorção se dá na recepção das mensagens (essencialmente audiovisuais) no cérebro, onde um terço do córtex humano lida com as questões das imagens (Hoffman, 2015), órgão que canaliza e identifica as infinitas tonalidades, dimensões volumétricas, espaciais, escalas sonoras e cromáticas nos pontos de "entrada" do corpo humano, por meio dos seus canais sensitivos.

O cérebro do homem reconfigura espacialidades e realiza sinapses novas que permitem incorporar aprendizados diferenciados pois a maior parte da experiência passou a se materializar em plataformas comunicativas, em aplicativos digitais, em sistemas de redes o tempo todo conectados e onde, presencial ou virtualmente, os seres interagem com máquinas a partir de comandos hápticos, o que faz com que a internet em todas as coisas ${ }^{2}$ seja evidência incontestável. Nesse sentido, destaca-se a enorme dependência do ser (e do seu cérebro) na incontornável entrega para mergulhos na "sensualidade" dos equipamentos e dos aplicativos que estão disponíveis. Tal imersão se verifica sobretudo na sublimação das adversidades do mundo real, pois se constata que os atrativos tecnológicos envolvem o ser em dimensão sedutora e incontornável, uma vez que os chips estão inseridos em todos os aparatos que circundam o homem. E mesmo no seu corpo por

2 Ampliação do conceito de "internet das coisas" (Internet of things - IoT), largamente conhecido. 
comporem o conceito de wearable devices ${ }^{3}$. Essas configurações neurofisiológicas impulsionam os sentidos humanos para uma nova dimensão física (ampliação dos conceitos de espaço, tempo e navegação nos equipamentos) e cognitiva (explosão das várias formas de acesso e domínio do saber), e também na relação do homem com a sua essência. Nessa direção, no livro Cibernética e Sociedade, o uso humano de seres humanos, Norbert Wiener afirma que "a religião cristã e seus antecedentes mediterrânicos [...] incorporaram a noção de alma" (1954, p. 97) e adianta que "a mais interessante das primeiras explicações científicas da continuidade da alma é a de Leibniz, que concebe a alma como pertencente a uma classe mais vasta de substâncias espirituais permanentes, a que deu o nome de mônadas" (1954, p. 98). Essa dimensão analítica converge com o pensamento de Teilhard de Chardin que afirmou que a evolução fez surgir uma noogênese $e^{4}$ uma "camada nova, a 'camada pensante' que, após ter germinado nos fins do Terciário, se expande desde então por cima do mundo das Plantas e dos Animais: fora e acima da Biosfera, uma Noosfera" e em que "[...] a Terra 'muda de pele', [... encontra a sua alma" (Chardin, 2006, p. 197, grifos no original). Da mesma forma, na obra $O$ método 4, as ideias (2011), Edgar Morin usa largamente o termo espíritos/cérebros (p. 22, 23, 42 e outras) e aponta que "as representações, símbolos, mitos, ideias são englobados [...] pelas noções de cultura e de noosfera", sendo que "do ponto de vista da cultura, constituem a sua memória, os seus saberes, os seus programas, as suas crenças, os seus valores, as suas normas. Do ponto de vista da noosfera, são entidades feitas de substância espiritual e dotadas de certa existência” (2011, p. 141).

\section{Virtualidades contínuas}

Assunto central neste paper, apontamos que, por pervasivas, as tecnologias se tornaram imperceptíveis e se metamorfosearam no ambiente humano, o que contribui para que as capacidades cerebrais fossem expandidas em todas as direções de sua singularidade. Partimos do pressuposto de que as contínuas simbioses humano-equipamentos inseriram relações sinápticas cerebrais novas que permitiram que, com a mediação incessante de máquinas, o ser pudesse alcançar e extrair o conhecimento buscado. Assim, em

3 Tradução: equipamentos vestíveis.

4 Em nota de rodapé, Chardin define noogênese como derivado do grego noûs, sentido para espírito, psique. 
um sutil e contínuo processo de plasticidade biológica, novas habilidades e consequentes abstrações conceituais passaram a integrar o cérebro humano, uma vez que o aprendizado das novas plataformas aumentou ou reconfigurou partes dele. Essas alterações compõem o vasto e intenso processo de microadaptações visto que atraentes opções passaram a materializar as novas dimensões informativas ressignificando as composições espaciais e implodindo as distâncias e a noção de tempo. Atraentes displays cibervisivos (todas as telas estão on-line) reconfiguram a síntese comunicativa, sobretudo a experiência de ver televisão, ouvir rádio, ler jornais e periódicos, dialogar em aparelhos de telefonia, fazer compras, trocar correspondências ao mergulhar as pessoas em vivências oníricas nas vibrantes plataformas de jogos inacreditavelmente reais. Ressalta-se que todos esses processos comunicativos se efetivam no cérebro humano.

Nessa base epistemológica e visando alargar conceitos sobre os processos cognitivos comunicativos, torna-se prudente incluir saberes interdisciplinares uma vez que se diagnostica um intenso processo simbiótico entre o ser e a máquina, fato que promove o acesso ao conhecimento por meio das interações homem-máquina (IHC). Além da histórica relação osmótica do homem com os muitos aparelhos-máquinas, destacamos a importância da dimensão abstrata da virtualidade, na qual as redes despontam como recursos indispensáveis para a cibernética e que, pelas muitas formas de atracamentos, dinamiza a promoção do conhecimento individual ou coletivo. Nesse sentido, na obra Decodificando o Universo (2010), Charles Seife lembra que "não somos fundamentalmente diferentes de uma máquina de Turing ou de um computador" (p. 237), conceito também presente no magistral livro O homem máquina (2013), do médico alemão Fritz Kahn (de fato, obra de 1926), que entendia o corpo humano como uma fábrica plena de equipamentos. Tais raciocínios oferecem as bases para Edgar Morin inserir a "metáfora do Grande Computador" (2011, p. 122) apontando que "estamos na aurora de um formidável desenvolvimento da cerebralidade artificial em redes” (p. 23), condição que permite ao ser o

sentido de um pensamento complexo, único a poder reforçar e desenvolver a autonomia pensante e a reflexão consciente dos indivíduos, único a permitir a cada um edificar em si mesmo os observatórios 
dos metapontos de vista, único capaz de reconhecer os seus próprios buracos negros, único capaz de acionar a dialógica entre o global e 0 particular, a parte e 0 todo, o objetividade científica e a reflexividade fiIosófica, único capaz de considerar sem trégua o horizonte planetário e, além, os aléns. (Morin, 2011, p. 125, grifo no original)

As lógicas do pensamento residem nos cérebros humanos e são codificadas à sua semelhança nas semânticas técnicas que compõem as máquinas. Os sinais de uma abrangente virtualização são irrecusáveis e a inserção social está levando a humanidade a um novo patamar de experiência cognitiva, agora sensorialmente coletiva e emaranhada, que varia da dimensão real àquela metafísica. Isso, pois, se desenvolveram novos níveis de abstração espacial e temporal, predicados fundamentais para a compreensão da virtualidade que a todos envolve. Assim, ao focar algumas das matizes das materialidades da comunicação, torna-se pertinente a realização de mergulho investigativo interdisciplinar, o que possibilitou alargamento dos referenciais teóricos. Tal abertura permitiu ancoragem em outras áreas do saber na procura pela estruturação de bases que elucidassem os processos de captação e absorção de conhecimento no cérebro humano. As investigações revelaram que estudos importantes vêm sendo feitos na Neurociência e na Psicologia, especificamente no segmento da Psicologia Cognitiva. Nesse aspecto, ao citar Ulric Neisser no livro Psicologia cognitiva, Robert J. Sternberg define o termo como "o estudo de como as pessoas aprendem, organizam, armazenam e utilizam o conhecimento" (2010, p. 10), e aponta que "no fim da década de 1950, alguns psicólogos estavam intrigados pela incômoda ideia de que as máquinas poderiam ser programadas para demonstrar o processamento inteligente da informação" (2010, p. 10). O autor afirma que os postulados de Shannon e Weaver ${ }^{5}$ tinham sido fundamentais para eles e que "a teoria da informação, [...] buscava entender o comportamento das pessoas sobre como elas elaboram os tipos de elementos de informação processada pelos computadores" (2010, p. 10), e lembrava que esta tinha sido de grande importância na publicidade. Esse autor aponta ainda o linguista Noam Chomsky e destaca Alan Turing, que havia sugerido que, "em pouco tempo seria difícil distinguir a comunicação das máquinas da dos seres humanos" (2010, p. 9).

5 Autores da Teoria Matemática da Comunicação. 


\section{As redes e a osmose máquinas-cérebros humanos}

Na obra A teia da vida, Fritjof Capra lembra que "a concepção de rede foi a chave para os recentes avanços na compreensão científica não apenas dos ecossistemas, mas também da própria natureza da vida" (1996, p. 45). Ao assimilar essa instigante afirmação, depreendemos que, sedimentado na estrutura biológica dos seres, os processos ininterruptos de trocas informativas constituem a essência de tudo, o que permite que a ciência estude e organize seus princípios, sejam eles eminentemente físicos, sejam imateriais. Tais pressupostos influenciaram os estudos da Cibernética, que estruturam princípios nas observações sobre o funcionamento dos organismos e das máquinas ${ }^{6}$, especificamente quando Norbert Wiener define que "é certamente verdade que o sistema social é uma organização semelhante ao indivíduo, que é mantido coeso por meio de um sistema de comunicação" (1954, p. 63). Robert J. Sternberg adiciona que "os neurônios tendem a se organizar na forma de redes que se interligam, trocando informações e promovendo vários tipos de processamento da informação" (2010, p. 30).

O autor da instigante obra A era das máquinas espirituais (2007), Ray Kurzweil, prevê que o homem se fundirá com a tecnologia, no conceito denominado transumano, quando este passará a ter nanobots (robôs em escala nanométrica) em seu corpo, em hibridização de inteligências biológica e não biológica. $\mathrm{O}$ autor crê em uma teia cerebral, pois "haverá uma rede invisível de computadores profundamente integrados no ambiente, em nossos corpos e dentro do nosso próprio cérebro" (Anderáos, 2006, p. L10). Concretamente, fala dos predicados da Inteligência Artificial uma vez que "será difícil saber onde acabam os seres humanos e começam as máquinas" (Anderáos, 2006, p. L10). McLuhan falou das "próteses” que o ser estaria usando um dia e hoje sabemos que a implantação de instrumentos no corpo humano já é realidade visto que as redes digitais são uma das

6 A Cibernética é a ciência que estuda as comunicações e os sistemas de controle não só nos organismos vivos, mas também nas máquinas. 
consequências da evolução das tecnologias comunicativas. Seu amplíssimo uso em praticamente todas as atividades da humanidade pode ter favorecido a constituição de uma sutil teia tecnocerebral que, a partir das tecnologias ubíquas e perenes do momento, estaria materializando uma internet "de mentes", princípio que acrescenta aos conceitos de internet "de e das coisas". Nesse sentido, Sue Halpern relata que, após ter implantes cocleares inseridos nos ouvidos, o cientista Michael Chorost sugeriu a ousada proposta de se "instalar computadores intracerebrais em todos", o que permitiria que a internet "seria parte integral do ser humano e seu uso seria tão natural quanto o de nossas próprias mãos” (Halpern, 2011). Elas seriam sensíveis ao humor dos humanos e introduziriam o conceito de "computação afetiva”. Na mesma direção, no artigo "The next front of wearables”, Erez Podoly refere-se a uma "internet of $m e$ " (2015), um novo recorte temático no qual a pesquisadora Rosalind Picard estuda as "formas de atribuir habilidades emocionais ao computador para que a máquina tenha capacidade de responder de forma inteligente às emoções humanas" (Leal, 2011, p. 57). Dessa forma, entendemos que se abrem perspectivas para estudos que investiguem as evoluções técnicas que permitem que os seres interajam com as máquinas a partir dos seus sentidos e façam com que estas reconheçam e ajam de acordo com as emoções dos usuários. A jornalista Dinorah Ereno descreve pesquisas que estão sendo desenvolvidas no Brasil para "captar expressões faciais" através de equipamentos que "poderão identificar as emoções do usuário, interpretá-las em tempo real e reagir de modo inteligente" (2015, p. 62) ao medir os batimentos cardíacos, a pressão arterial e a condutividade elétrica da pele das pessoas. Estes são conhecimentos importantes, pois as alterações físico-biológicas internas emitidas pelo corpo humano indicam o grau emotivo de aceitação, de repulsa etc. quando exposto a diferentes situações. Destacamos que todos estes são conhecimentos fundamentais para a comunicação uma vez que esta requer identificação entre emissor e receptor.

Ao abordar a emotividade, Kurzweil acrescenta instigante questão ao apontar uma parte profunda e pouco acessível do cérebro humano e relata experiências desenvolvidas por neurocientistas que, ao estudarem padrões de epilepsia, descobriram "um pequeno lócus de neurônios no lobo 
frontal, que parece ser ativado durante as experiências religiosas” (2007, p. 211). Essa descoberta se revela importante, pois "uma base neurológica para a experiência espiritual tem sido postulada há muito tempo pelos biólogos evolucionistas" (2007, p. 211), pois introduz o conceito de Noética, definida como a ciência que estuda os fenômenos da consciência. Em tais bases científicas, indagamos se, ao incorporar simbioses tecnológicas sutis e perenes, estas não estariam sendo "fundidas" à constituição humana, o que indica que as próteses corpóreas e os exoesqueletos são exemplos disso. Indo além, interpomos se a ubiquidade das tecnologias e as alterações cerebrais experimentadas pelos humanos oferecem o caminho para uma malha estruturada em dialogicidades mentais, que adicione nessa dimensão as formas comunicativas existentes. Se essas premissas se confirmam (conforme estudos na Física e na Neurociência), uma profunda hibridização homem-máquina estaria em processo ao partilhar processos comunicativos entre instrumentos e mentes em um modelo que poderia ser definido como técnico-biológico-espiritual. Com implantes corpóreos perenemente conectados, as malhas já ligam as mentes humanas às máquinas, baseadas no mesmo princípio como estas fazem por meio das conexões wi-fi domésticas. Indaga-se se os equipamentos conectarão as mentes humanas para o intercâmbio de conteúdos audiovisuais, sem os comandos físicos (dedos, movimentos, voz e olhar), mas unicamente pelo pensamento, como já se faz na Neurociência. Ou na Física, conforme relata o cientista Michio Kaku na obra $A$ Física do futuro (2011), ao adicionar uma afirmação instigante: "A rápida ascensão da capacidade computacional lá pelos anos 2100 nos dará um poder igual ao dos deuses da mitologia que adoramos no passado permitindo-nos controlar o mundo à nossa volta com o simples pensamento" (2011, p. 39). Kaku fala de computação ubíqua (2011, p. 49), Realidade aumentada (2011, p. 59), tecnologia tátil (2011, p. 50) para introduzir o conceito de singularidade ao lembrar que "tal palavra veio do mundo da física relativista” e que "a ideia de uma singularidade de IA (Inteligência Artificial) foi mencionada pela primeira vez em 1958” em uma conversa entre "dois matemáticos Stanislaw Ulan e John von Neumann [...] foram ampliadas e popularizadas pelo escritor de ficção científica e matemático Vernon Vinge" (2011, p. 123). Esses assuntos são relevantes para o futuro da comunicação, setor altamente dependente de máquinas. 


\section{Máquinas que entendem pensamentos humanos}

Máquinas superpotentes já conseguem processar dados em velocidade próxima à do cérebro, principalmente em ações de movimentos e audição. Neurocientistas sinalizam que as máquinas já superam algumas limitações corpóreas reais, como na adição de adereços que se integram ao organismo humano (tecnologias vestíveis) e ao atender a comandos emitidos exclusivamente pelas mentes de seres com deficiências físicas radicais. É o que vem acontecendo em estudos que focam a "exploração das interfaces cérebromáquinas que tem provocado uma verdadeira corrida entre neurocientistas de todo o mundo" (Miranda, 2012, p. C5).Já existem as próteses controladas apenas pelos pensamentos e uma pesquisa demonstrou que, a partir de eletrodos implantados no córtex motor de uma paciente tetraplégica, o maquinário detectou e transmitiu pensamentos elaborados unicamente pela mente dela acionando uma mão robótica externa. Este é um experimento muito importante, pois se trata do inédito processo de o comando ter sido originado no cérebro de um ser humano e compreendido, por conexão web, por máquinas que assimilaram e cumpriram a ordem "empacotada" no pensamento. No ano de 2010 em palestra no Technology, Entertainment, Design (TED), a cientista Tan Le apresentou o e-motiv (Le, 2010), um sistema de tecnologias denominado de interfaces cérebro-computador que lê pensamentos humanos e os transmite à distância. Importante reconhecer que essas possibilidades inserem um questão delicada e muito preocupante, de natureza ética, que é a chance de a comunicação entre mentes permitir a um dos lados (ou a muitos) o domínio das personalidades mais fracas, despreparadas, ingênuas etc. ou ainda adentrarem dimensões das mentes que deveriam ser mantidas preservadas. Pela complexidade de tais situações, restringimo-nos às reflexões dos processos entre homens e máquinas, estando este no comando do processo e no princípio do acesso aos bens comunicativos alocados em bancos de dados. Da mesma forma, desviamos de julgamentos de qualquer teor sobre as vantagens e perigos da relação do homem com as máquinas, por isto não ser o foco presente.

Dessa forma, enfatizamos que, neste paper, miramos a comunicação por meio do pensamento na relação entre os seres humanos e os equipamentos que disponibilizam as narrativas, os aplicativos e os processos cog- 
nitivos estruturados. Partimos do princípio que as bases teóricas de outros campos científicos ajudarão na criação de procedimentos similares nos estudos comunicacionais. Lembramos que a Teoria Matemática de Shannon e Weaver teve suas origens no mundo concreto da engenharia; além disso, estudiosos entenderam e definiram as qualidades da emissão, transmissão e recepção de conteúdos de e para seres humanos. Adicionamos que a comunicação e todo o processo industrial de criar, editar, arquivar e difundir conhecimento estão estruturados no mundo físico (entre homens e máquinas), justamente aquele dos processos mecânicos, em sistemas interligados por cabos elétricos, com máquinas que imprimem textos em folhas virgens, com aparelhos que enviam sinais em ondas de rádio para receptores audiovisuais. Nessas máquinas, sabe-se que a comunicação se materializa em equipamentos físicos e é pressuposto de concretização a interação do ser humano, seja como emissor, seja como receptor.

A hegemonia desse processo durou muitas décadas, mas está mudando, uma vez que máquinas informatizadas de comunicação entendem, além dos comandos em toques nos teclados e telas, também os emitidos pela voz humana (Siri, tradutores instantâneos etc.), gestos humanos (Kinect) e mais recentemente o aplicativo chamado Eye-Tracking ${ }^{7}$ (Etherington, 2015). Esses exemplos mostram que a interação física está evoluindo e sendo substituída por outras formas de inserção de comandos, agora também aquelas oriundas pelas mentalizações digitalmente mediadas por próteses que realizam a leitura das sinapses elaboradas nos cérebros humanos. Fala-se da possibilidade de emissão de conteúdos por meio de construção mental que, após a elaboração e a codificação dos enunciados, e de sensores elétricos colocados nas cabeças de seres humanos, as mensagens sejam transmitidas por conexões diretamente para máquinas receptoras. Trata-se da transmissão de um comando mentalmente construído, que é enviado por redes intraconectadas (como os sinais wi-fi), mas sem o toque humano em telas ou mediadores de sinais de entrada (teclados, controles remotos etc.), ou ainda sem a voz e os gestos humanos. Só com o pensamento. Entendemos que essa concepção tem pertinência científica, mas estamos cientes de que algumas questões despontam. Afinal, como entregar ao receptor os produtos audiovisuais

7 Tradução: rastreador de olhos. 
(programas de TV, documentários, jornais etc.) sem alguma forma de mídia? Sabemos que é mais assimilável a lógica da transmissão de conteúdos sonoros de e para cérebros dos interagentes e resgatamos a lógica da transmissão de conteúdos orais entre duas pessoas, em que, após a emissão da mensagem, o cérebro do receptor é estimulado a criar conteúdos imagéticos correspondentes ao enunciado original. Isso se dá na comunicação oral pessoal e no processo mediado por máquinas (telefone, aplicativos etc.), no qual a mensagem sonora cria imagens mentais no receptor, que se esforça na reconstrução de significados os mais próximos da intenção inicial.

Tal processo é útil para avançar no presente intento, pois no caso do conteúdo sonoro, o pensamento codificado do emissor estimula a criação de enunciados "mediados" pelas tecnologias das redes digitais com significados enviados para a mente do receptor, em processo que poderia ser definido como telepático, conceito "emprestado" da Psiquiatria e da Psicofísica, sobretudo nos estudos sobre paranormalidade. Charles Seife reconhece que ainda é difícil criar uma teoria para a telepatia, pois não se sabe que "mecanismos permitiriam que as mentes das pessoas se conectassem umas às outras" (2010, p. 246). Todavia, a cientista Leslie Horn relatou que suas pesquisas "demonstraram com sucesso uma interface cérebro-acérebro em um estudo com seis pessoas. É a segunda versão desse estudo, [...] sendo suficiente para presumir que a telepatia poderá sair do mundo da ficção científica", também na internet (2014). A pesquisadora pretende saber se, um dia, "um professor conseguirá enviar informações diretamente para o cérebro de um estudante" (2014). Reforçamos que esses cenários desenham possibilidades tanto instigantes quanto aterradoras, que justifcam prever o estabelecimento de protocolos que preservem as dimensões éticas e morais que seguramente se interporão para todas as formas de conexões, as mentais incluídas.

Isso posto, objetivamente retornamos à indagação central que aqui trabalhamos, que é saber se as pessoas acessarão mentalmente os variados meios de comunicação sem a necessidade "física" destes. Essa questão apresenta dificuldades na atualidade, pois se sabe que a síntese da comunicação 
consiste em codificar e enviar significados de um para outro ser humano, em processo que na comunicação massiva é intermediado por plataformas em que os conteúdos de materializam (folha do impresso, aparelho de TV ou de rádio etc.). Nesse modelo, a mensagem sonora (uma frase, por exemplo) é constituída de palavras que, após emitidas, são reconstruídas na mente do receptor e criam imagens correspondentes para a compreensão do enunciado original. E, no caso da paciente aqui relatado, resumese a frase mental, que é composta por palavras que atuam como linhas de comando para a máquina que recebe a mensagem. Atualmente, já foi alcançado estágio em que o processo se completa, pois já existe retorno em forma de mensagem emitida pela máquina para o cérebro do emissor que, além de cumprir a ação por ele demandada, lhe passa detalhes do objeto analisado.

Apesar das limitações que ainda se impõem, mas conscientes de que tais possibilidades podem ser superadas em futuro próximo, consideramos que a evolução tecnológica em sistemas de processamento e transmissão ultrapotentes sinaliza transformações radicais nas formas de contato de humanos com as máquinas, a partir da mediação de aplicativos conectados. Avaliando as descobertas de alguns cientistas, concluímos que serão cenários assimiláveis pelas demais áreas. Dessa forma, as descobertas científicas aqui relatadas poderão configurar uma radical mudança nas bases da comunicação humana, pois tais inovações seguramente eliminarão as interfaces que ainda hoje intermediam os processos de envio e trocas de significados, sejam estes entre os homens e os equipamentos, sejam entre as máquinas. Antevemos que, em se tornando reais, estas descartarão a própria essência da atividade comunicacional "clássica" dos dias atuais, em que estão as empresas midiáticas que elaboram e vendem conteúdos informativos. Nesse novo cenário, as empresas como as conhecemos na atualidade deverão ser fortemente reconfiguradas e prenunciamos que se tornarão fornecedoras de conteúdos virtuais alocados nas "nuvens" (e acessíveis o tempo todo, em multiplataformas), como fazem as empresas de informática. Acreditamos que este deverá ser o caminho inevitável, pois se sabe que, pelo menos no caso das emissoras de televisão, transformações gigantescas se anunciam na arte de produzir e assistir a programas televisivos (Squirra, 2013), que 
eliminam a grade de programação e a dependência dos intervalos comerciais. Destacamos a chegada da NetFlix e da Amazon, que reconfiguraram a arte de produzir séries e conquistar audiências, o que criou o termo binge-watching para definir os que "não conseguem parar de assistir aos programas".

Os comandos midiáticos por meio do pensamento, processo em estímulos elétricos sinápticos que transformam os protocolos da comunicação, inserem novas narrativas, inéditas linguagens, impensáveis processos de interação e inauditas plataformas comunicativas. São caminhos que intrigam e estimulam uma vez que revelam que o homem passa por um momento inovador na sua relação com as máquinas, seus aplicativos e com o conhecimento por elas proporcionado. A velocidade da vida moderna permite intercâmbios muito mais rápidos, eficientes e simples, em multiplicidades de exposição de conteúdos em que o ciberespaço abre caminho para as conexões exponenciadas da atualidade. Nesse sentido, vale indicar as descobertas científicas de Miguel Nicolelis no livro Muito além do nosso eu (2011) e em palestra do TED com título "A comunicação cérebro-a-cérebro justamente chegou" $(2015)^{8}$, que afirmou que, através de próteses neurocorticais, com equipamentos leitores eletroencefálicos, já era possível receber sinais de retorno (o feedback), pois o jogador que esteve na abertura da Copa do Mundo de 2014, por exemplo, podia "sentir o chão" em que pisava, o que nos leva a lembrar que, em pouco tempo, nossos descendentes "poderão navegar pela rede só com pensamentos".

\section{Conclusões}

Neste texto, praticamos a abertura investigativa com ampliação interdisciplinar das referências com vistas a entender os caminhos possíveis para a comunicação no futuro. A reconfiguração neurobiológica alargou os padrões cognitivos humanos, o que aponta que, com comandos mentais e recursos técnico-comunicativos incrustados no corpo, o homem será capaz de se comunicar com a profusão de máquinas que o rodeia, pois se exponencia a inteligência embutida nas máquinas. Quando as inovações forem largamente incorporadas, toda a área da "indústria cultural" da comunicação

\footnotetext{
8 Em inglês: "brain-to-brain communication has just arrived".

9 Em inglês: "surf the net just by thinking".
} 
(emissoras de rádio e de TV, jornais, revistas etc.) deverá sofrer ampla reestruturação uma vez que os processos comunicativos serão realizados de forma múltipla, inclusive mentalmente, sem a intermediação dos aparatos de materialização de conteúdos da atualidade. Aliás, a arte de materializar conteúdos audiovisuais já é viável em variadas bases midiáticas móveis e conectadas -os displays aqui apontados-, como é o caso das impensáveis visualizações através de nanolentes inseridas nos olhos humanos.

Entendemos que se avizinha a chegada de um processo comunicativo inimaginável, que incorpora as dialogicidades homem-máquina já alcançadas na robótica e na neurociência, e projeta-se um inédito cenário em que a comunicação se dará de cérebro para máquinas, e tão importante quanto de máquinas para cérebros (pressuposto da inteligência artificial), em que com o uso de tecnologias vestíveis ubíquas os seres passarão a consultar os repositórios noticiosos de jornais, emissoras de rádio e televisão etc. por meio de comandos mentais, que eliminam os processos hápticos e cinéticos da atualidade. Tal possibilidade alterará os acessos aos produtos da comunicação, pois estes se darão a partir de comandos mentais para máquinas que disponibilizam os conteúdos alocados nas bases midiáticas nas nuvens. Em proposta de alargamento teórico-conceitual e conscientes das abrangências sociais do tema, evitamos adentrar às questões éticas, culturais, morais, de tal configuração visto que isso requereria suportes teóricos e aprofundamentos específicos. Outrossim, distantes de uma análise acrítica, entendemos que a velocidade das descobertas científicas e os avanços da Neurociência se configuram como balizadores de estudos como o aqui delineado pois, quando as simbioses homem-máquinas forem expandidas, poderão representar a implosão do modelo midiático largamente praticado, consumido e estudado por mais de seis décadas. Entendemos que o recorte temático aqui praticado acena possibilidades de migração para as comunicações no futuro e reconhecemos que merece outras incursões científicas que levem o tema ainda mais à frente. 


\section{Referências}

Anderáos, R. (2006 13 nov. 2006). O profeta das máquinas espirituais. Folha de S.Paulo/Link, L10.

Bagdikian, B. (1993). O monopólio da mídia. São Paulo: Página Aberta.

Bliss Jr., E. (1991). Now the news. Nova York: Columbia University Press.

Canton, J. (2001). Technofutures. São Paulo: BestSeller.

Capra, F. (1996). A teia da vida. São Paulo: Cultrix.

Castells, M. (1999). A sociedade em rede. São Paulo: Paz e Terra.

Castells, M. (2003). A galáxia da internet. Rio de Janeiro: Jorge Zahar.

Chardin, P. T. (2006). O fenômeno humano. São Paulo: Cultrix.

Dertouzos, M. (1997). O que será. São Paulo: Companhia das Letras.

Ereno, D. (2015 jan.). Emoções catalogadas. Revista Fapesp, 62. Recuperado em 12 jun. 2015 de http://revistapesquisa.fapesp.br/2015/01/19/ emocoes-catalogadas/

Etherington, D. (2015). Apple Patents Eye-Tracking And Visual Control Tech For Mac, iOS And Beyond, de 20 jan. 2015. Recuperado em 23 abril 2015 de http://techcrunch.com/2015/01/20/apple-patents-eyetracking-and-visual-control-tech-for-mac-ios-and-beyond/

Gilder, G. (2001). Telecosmo. Rio de Janeiro: Campus.

Halpern, S. (2011 20 jun. 2011). Cérebro: no controle ou controlado. OESP/Link/The New York Review of Books, p. L6. 
Head, S. e Sterling, C. (1990). Broadcasting in America. Boston: Houghton Mifflin Co.

Hoffman, D. (2015). Does we see reality as it is? TED Talks. Recuperado em 12 set. 2015 de http://www.ted.com/talks/donald_hoffman_do_ we_see_reality_as_it_is\#t-4661

Horn, L. (2014). A telepatia através da internet está prestes a se tornar realidade. Recuperado em 7 set. 2015 de http://m.gizmodo.uol.com. $\mathrm{br} /$ telepatia-pela-internet

Jenkins, H. (2009). Cultura da convergência. São Paulo: Aleph.

Jenkins, H. (2014). Cultura da conexão. São Paulo: Aleph.

Johnson, S. (2001). Cultura da interface. Rio de janeiro: Jorge Zahar.

Kahn, F. (2013). O homem-máquina. Koln: Taschen.

Kaku, M. (2012). A física do futuro. Rio de Janeiro: Rocco.

Kurzweil, R. (2007). A era das máquinas espirituais. São Paulo: Aleph.

Le, T. (2010). A headset that reads your brainwaves. Recuperado em 22 nov. 2011 de http://www.ted.com/talks/tan_le_a_headset_that_reads_your_brainwaves

Leal, R. (2011 abril). Máquinas têm sentimentos? Revista Info, 57.

Machado, A. (2000). A televisão levada a sério. São Paulo: Senac, 2000.

Mattelart, A. (2002). História da sociedade da informação. São Paulo: Loyola.

Mattelart, A. e Mattelart, M. (2003). História das teorias da comunicação. São Paulo: Loyola. 
McLuhan, M. (1964). Os meios de comunicação como extensões do homem. São Paulo: Cultrix.

Miranda, G. (2012 17 dez. 2012). Mulher controla mão-robô com a mente. Folha de S.Paulo, Saúde + Ciência, p. C5.

Morin, E. (2011). O método 4. As ideias, habitat, vida, costumes, organização. Porto Alegre: Sulina.

Nicolelis, M. (2011). Muito além do nosso eu. São Paulo: Companhia das Letras.

Nicolelis, M. (2015). A comunicação cérebro-a-cérebro justamente chegou. Recuperado em 3 fev. 2015 de https://www.ted.com/talks/miguel_nicolelis_brain_to_brain_communication_has_arrived_ how_we_did_it/transcript

Pavlik, J. (2008). Media in the digital age. Nova York: Columbia University Press.

Podoly, E. (2015). The next front of wearables. Recuperado em 2 mar. 2015 de http://techcrunch.com/2015/01/28/the-next-front-of-wearables/

Rifkin, J. (2001). A era do acesso. São Paulo: Makron Books.

Seife, C. (2010). Decodificando o universo. Rio de Janeiro: Rocco.

Squirra, S. (2013). O futuro da TV na fusão tecnológica que tudo altera. Revista de Radio Difusão da SET-Sociedade de Engenharia de TV, 7(7), 21-27. Recuperado em 22 abril 2014 de http://www.set. com.br/revistaeletronica/radiodifusao/index.php/revistaderadiodifusaoset/article/view/77

Sternberg, R. (2010). Psicologia cognitiva. São Paulo: Cengage Learning.

Toffler, A. (1992). A terceira onda. Rio de Janeiro: Record. 
Vilches, L. (2003). A migração digital. São Paulo: Loyola.

Wiener, N. (1954). Cibernética e sociedade. O uso humano de seres humanos. São Paulo: Cultrix.

Wolton, D. (2000). Internet, et aprés? Paris: Flamarion. 